\title{
Research on Transport Development of Railway Container Technology
}

\author{
Zhian Yin \\ Nanchang Institute of Science \& Technology
}

Keywords: Railway Container; Transport Development; Feasible Suggestions; Multi-modal Transport

\begin{abstract}
With the continuous growth of international trade, one of logistic main forces - container transport have undergone dramatic changes in its mode and demands, the transport center has gradually shifted from Europe and America to Asian-Pacific region, and the railway container transport has also taken a place in the mainstream container shipping and truck transportation on highways. This paper describes that the emergence of container has changed the traditional forms of cargo transportation and played key roles in the cargo transport of international trade, and gives a definition of container transport. The inland port development of railway container faces many issues, for example, how to give full play to railway container transport, expand the radiation scope of railway container transport, promote the advancements in domestic container multi-modal transport and stimulate the development of railway container multi-modal transport.
\end{abstract}

\section{Introduction}

The emergence of container has changed the traditional forms of cargo transportation, playing key roles in the cargo transport of international trade. Container transport is based on mass production, takes such a large container as the carrier, and assembles the cargo into assembly unit, so as to use large loading machines and large transport vehicles for loading, unloading, handling and completing the transport tasks. In such a way, a new efficient and cost-effective mode of transport will be achieved for "door-to-door" cargo transport.

Compared with developed countries, the development of China's railway container transport lags behind, and the transport organization modes and operation management mode are restricted to some extent. In addition, China's inland container transport is faced with poor collection and distribution conditions and inefficient coordination and link between all modes of transport and all regions. The organization and operation of railway container transport as well as coordination between the railways, roads, sea transport and ports have important significance to the entire container transport system. This paper introduces the features, mode of transport, transport equipment and development advantages of railway container multi-modal transport in developed countries, comparatively analyzes the current situation and equipment of domestic railway container transport, and proposes the development ideas for organization mode and transport equipment of domestic railway container multi-modal transport.

\section{Problems Existing in China's Railway Container Transport System}

Long Time for Container Turnover. Due to the existing technology and management methods, it is impossible to efficiently track and manage the container off-site dwell time and postponed use, and unable to timely track the heavy empty containers. Restricted by traffic flow and transport capacity, a large number of containers are occupied for free and stayed for an indefinite period, which seriously affect the container turnover and lead to failed exit of heavy containers and failed return of empty containers. At the same time, the container transport cannot be guaranteed and containers failed to reach in time, resulting in frequent complaints from cargo owners.

Relatively Slow Development of Special Railway Vehicles. There are obviously insufficient special container flat wagons and ordinary vehicle substitutes, leading to fighting for vehicles and capacity between containers and ordinary cargo. Currently, there are less special X6A, X6B vehicles suitable for container transport. Besides, special equipment adapt to international TEU loading is inadequate, which reduces the loading speed and efficiency, causes serious damage to 
TEU and existing handling machines, and increases the transportation costs.

Information System's Failure to Meet International Container Transport Needs. For research and use of container transport information system, the railway is still weak in this regard, and cargo ticket processing still adopts outdated methods. The railway departments are unable to effectively manage international container information, fail to provide the necessary information to customers, and cannot exchange data with ports, customs and other relevant departments.

\section{Technology of Railway Container Multi-modal Transport}

One of the advantages of container transport is multimodal transport. International container multi-modal transport integrates with railways, roads, waterways and other means, and implements one-consigned, one-ticket, once-charged, once-insured, and full-responsible "door-to-door" services. During the transport, the advanced EDI (electronic data interchange) system plays an important role in tracking management. In North America and Europe, international multi-modal transport system based on container is considered to be a revolution in the organization and management of transport system. Since the 1980s, the multi-modal transport has become an international trend and fashion for container transport.

From the start-up of world container transport to the development of multi-modal transport, it has undergone nearly 30 years. Meanwhile, the railway container transport vehicles have also gone through the development courses of long undercarriage container flatcar, piggyback trucks, articulated container transport vehicles, double-decker container cars, and road-rail cars. Among these, piggyback trucks and road-rail cars are major means of container multi-modal transport. Railway container transport mainly consists of two forms, namely, Container on Flat Car (COFC) and Container Trailers on Flat Car (TOFC).

\section{Suggestions on Development of Railway Container Transport}

Reform of Management System and Increase in Market Functions. The information system should be improved. First of all, information sharing should be realized between all container handling stations, in order to keep abreast of empty containers, heavy containers, quantity and other temporary situations. This not only helps the rational flow of containers and enhances the utilization of containers, but also facilitates the lateral monitoring and control, and improves the supervision and inspection mechanism. Secondly, the information of railway traffic control system should be released conditionally. The professional railway scheduling system should orient to the market, enhance efficiency, upgrade equipment, and conditionally release the railway transport conditionally.

Change of Ideas and Reinforcement of Coordination with Multi-modal Transport System. Development of multi-modal transport is the main content of the railway container transport. Currently, all sides hope to cooperate with the railways for container transport, but they do not understand foreign container facilities, management, information and costs. In addition, the railway development is confronted with inadequate capitals and backward management technology. It is recommended to carry out foreign trade from the following aspects: Railways should be market-oriented and actively explore new sources. In the main body of container transport industry, the railway departments should take the initiative to think of customers and provide fast reliable services. Besides, they should implement direct customs clearance transport over the imported and exported containers, give play to the advantages of container multi-modal transport, promote the logistics cooperation based on the principle of mutual benefits, foster and expand the appropriate container supply of goods.

Renovation of Railway Container Information Management System. Through renovation and new construction, the container management information system will present a whole new look. By then, paperless office and information networking of the entire system will be achieved. The computers will be used to grasp the application, repair and scrapping status of various containers, special vehicles and tarpaulin. Scientific management and decision-making will be implemented. 
Above all, the use of information system to guide container transport production will greatly improve efficiency, and facilitate managers to organize and plan the transport production and improvements energetically.

\section{Conclusion}

If the railway achieves "door-to-door" transport services, this will facilitate the railway departments to optimize the logistics network layout and product structure, in order to achieve extension of service functions and innovation of logistics business model. According to railway development plan, the whole road will focus on the adjustment of site layout, coordinate with the construction of road network and double container channels, and form a railway container transport support system with 18 railway container logistics centers as the hub, 33 specialized container stations as nodes, train lines as the channel, which radiates across the whole country. During the "12th Five-Year Plan", the railway container transport will definitely get substantial growth. Under such circumstances, development and research of a new generation of transport technology mean and transport technology device that covers the current world railway technological progress and latest ideas of modern logistics, including piggyback container transport special vehicles, will have a positive significance in promoting the advancements in railway transport equipment, stimulating the reform of railway transport organization, establishing the modern highway-railway combined transport system and implementing the diversified transport services.

\section{References}

[1] Caçola P M, Gabbard C, Montebelo M I, et al. Research on City transport Development Strategy for Beijing (Part 1) [J]. transport Research Part B Methodological, 2010, 44(1):152-174.

[2] Yao Y U. Research on Development Countermeasures of Railway Container transport [J]. Railway Freight Transport, 2011.

[3] You-Lin L I, Wang H P, Sun X Q. Research on the Development of Container Rail-sea Combined Transport of Xiamen Port[J]. Logistics Sci-Tech, 2015.

[4] Chi C, Sun J P, Wei R. Research on Operation Process Control of Railway Refrigeration Container transport [J]. Railway Freight Transport, 2012.

[5] Wang L. Research on the Development Strategy of Logistics Firms in China [J]. Applied Mechanics \& Materials, 2014, 481(481):21-26.

[6] Yao Z. Research on Yingtan-Meizhou Railway as Double-deck Container transport Channels [J]. transport Science \& Technology, 2010.

[7] Lin J. Research on the Development Strategies of Sea-railway Combined transport by Container in Ports of Fujian Province [J]. Logistics Sci-Tech, 2013, 24(95):52-55.

[8] Li H. Research on Relationship Between Railway Container transport and Railway Freight transport Based on Association Analysis Method [J]. Journal of Shijiazhuang Tiedao University, 2013.

[9] Kin E B K A A, Bykodorov S A. Estimation of development prospects for the railway system in Russias transport Strategy [J]. Regional \& Local Studies, 2005, 49(1):13.

[10]Zu-Jie L I, Yang K, Wang S M. Research on Aided Decision Making System of railway container transport path [J]. Railway Computer Application, 2005.

[11] Xu S. The Advantages of Railway Container transport Development and Constraint Factors in China[C]// Third International Conference on transport Engineering (ICTE). 2011:2292-2297.

[12]Li H. Research on Travel Mode Share and Operation Strategy in Baoji-Lanzhou transport 
Corridor[J]. Journal of Information \& Computational Science, 2015, 12(4):1469-1478. 